\title{
Genetic medicine: an experiment in community-expert interaction
}

\author{
Renato Schibeci, Ian Barns, Robyn Shaw and Aidan Davison Murdoch University, Murdoch, Western
} Australia

\begin{abstract}
This project tested a two-way model of communication between lay groups and experts about genetic medicine in Perth, Western Australia. Focus group discussion with community group participants was followed by a communication workshop between community group participants and experts.

Four groups of concerns or themes emerged from discussion: clinical considerations; legislative concerns; research priorities, and ethical and wider considerations. Community group concerns are not always met by the actions of "experts". This is, in part, because of the differing life-worlds of each group. However, the communication workshop showed the potential of two-way communication for both lay and expert members in understanding the others'viewpoint. Further, the approach developed here offers one possible way for community groups to participate in a substantial way in policy formulation processes.
\end{abstract}

(Fournal of Medical Ethics 1999;25:335-339)

Keywords: Genetic medicine; gene technology; public understanding; public policy; health communication

The application of new gene technologies to human medicine takes place in the context of intense public interest, with both positive support for the prospect of more effective treatment of a range of human diseases, and fear and apprehension about a "brave new world" of genetic engineering. As far as most medical research scientists and medical practitioners are concerned, these fears are a result of media sensationalism and a lamentable public ignorance about the basic science involved, and are best met by more effective communication of information about scientific principles and technical procedures. However, as in other areas of gene technology, such as agricultural biotechnology, public ambivalence cannot be explained simply in terms of a lack of scientific understanding. Ordinary people are likely to view scientific developments more contextually, interpreting them within a range of broader concerns they may have about the political and cultural significance of science and medicine more generally.

In the light of this, effective public communication about developments in genetic medicine involves not just a one-way transmission of information from the experts to the public, but rather a two-way communication in which lay people are able to articulate their more general "life-world" concerns to the researchers and medical practitioners.

The creation of more dialogical forms of communication between experts and lay people has been attempted through the use of consensus conferences involving lay panels ${ }^{12}$ as well as focus groups and "peer conversation" groups. ${ }^{3}$ These various communication settings have enabled a much more open exploration of often inarticulate beliefs and values. ${ }^{4}$ Consensus conferences of the form developed in Denmark, the Netherlands and the United Kingdom have given lay people themselves the opportunity to set the agenda by formulating the questions they wish to raise about a specific topic in their own terms.

In this paper we report on a workshop involving expert-lay dialogue about developments in genetic medicine, specifically in relation to gene therapies for cystic fibrosis (CF). This workshop was the fourth and final phase of a three-year project on Public Perceptions of Biotechnology, conducted in Perth, Western Australia. The first two phases of this project involved the use of qualitative one-toone and focus-group interviews with representatives of "interested publics" in relation to the advent of two gene-technology products: the Flavr-Savr tomato, and the use of the growth hormone, pST, for improved pork production. The third phase involved the use of focus-group interviews to investigate the views of a more extensive range of community groups interested in the development of gene therapies for the treatment of cystic fibrosis. Since these interviews provided the immediate background to the genetechnology communication workshop and the basis for the selection of the group of lay 
participants, before discussing the workshop, we shall briefly outline what they involved.

\section{Background}

The aim of the earlier focus-group interviews was to explore in a more dialogical or conversational way the views of a range of "interested publics" on developments in genetic medicine. As a focus for discussion, we chose the development of gene therapies for cystic fibrosis. After contacting over one hundred associations in Perth, Western Australia with interests in community health issues, we eventually conducted focus-group discussions with 16 groups, representing a wide cross-section of disability support groups, community health groups and "belief" groups with concerns about medical ethics. At the beginning of each group discussion, the participants were provided with two sorts of stimulus and resource materials. The first was a "scenario" involving a couple planning to have a baby who were potentially carriers of the CF gene and who thus needed to consider a range of options, including genetic counselling and genetic diagnosis. The second involved a multimedia "information package" contained within a HyperCard stack on a Macintosh PowerBook. The information package was structured around a range of nine topics or question areas frequently raised in relation to genetic medicine. Using text and diagrams arranged under these topics, the package summarised a range of information, arguments and issues relevant to the development of gene therapy for cystic fibrosis. For each group, the information stack functioned as a resource and a stimulus for discussion. With the help of the group facilitator, each group was free to choose which of the nine categories it wished to explore, in what order and at what speed. The package was reviewed for accuracy by the local CF support group, a practising clinical geneticist and a representative of Genethics, a Melbourne-based, non-government organisation, which has been publicly critical of gene technology.

Sixteen focus-group discussions were conducted between 21 September 1996 and 15 March 1997 with a total of 95 individuals participating. The groups ranged in size from three to nine individuals. The discussions were held on the campus of Murdoch University. Each discussion was approximately two hours in duration and was facilitated by two research staff. The sessions were tape-recorded and transcribed.

\section{The workshop: aims, method and process} The aim of the gene-technology communication workshop was to continue the conversations begun in the separate focus groups, by enablin representatives from each of the groups to pos some of the questions raised in their grou discussion to a panel of experts. Although the model for the workshop was that of the consens conferences on biotechnology held in Europe an the UK in recent years, it differed in a number ways. Obviously, it was conducted on a much smaller scale and shorter time-frame. Mofe importantly, whereas, for example, the consenst $\vec{B}$ conference on plant biotechnology held in Lo $\vec{\omega}$ don in November 1994 deliberately drew of members of the general public with no previou active involvement in the issue, the purpose of ows

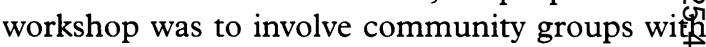
an active continuing interest in the issue ig conversation with the experts.

The workshop process involved two meetings after the completion of the series of focus groups. The first was a meeting (on 20 September 199 ) of representatives from the fourteen groups ab to participate in the workshop. The groups participating were: Health Network of WA; Cyste Fibrosis Association of WA; Birth Issues Group; SOMA Health Association; Huntington's Diseas Association of WA; Australian Family Assoc ation; Greenteach; Tourette Syndrome Organi ation; Buddhists; Humanist Society of WP Cancer Support Association; Haemophilia Foun dation; Catholics, and Protestant Christians. ThQ preliminary meeting provided the lay representa tives with an opportunity to meet each other, share the issues and concerns raised in their earli focus-group discussions and to formulate a seriơ of questions they wished to raise with a panel experts.

The workshop itself was held on 11 Octobes 1997 at Murdoch University, between twelve of these participants (representatives of Greenteach and Tourette Syndrome Organisation were noth present) and a reference panel with expertise various aspects of genetic medicine, public heal and medical ethics. The seven experts were: 요 medical geneticist who had wide experience counselling; a director of a bioethics centre; anatomist (an expert in human reproduction); $;$ judge of the federal court of Australia with a coid tinuing interest in law and genetics; a state government technology policy adviser with a pa: ticular interest in biotechnology policy issues; medical doctor with expertise in respirato medicine (who was conducting research in huma? gene therapy), and a senior policy officer in repro ductive technology with the Health Departmeôt of WA. 


\section{Lay questions}

The questions raised by the lay participants were considered in four thematic groups: clinical considerations; legislative concerns; research priorities, and wider considerations. The specific questions posed at the first meeting, plus additional background comment, had been circulated to the expert panel prior to the workshop. The series of questions were as follows:

\section{Theme 1: clinical considerations}

1) What are people's rights to privacy with respect to genetic information?

Do family members, among others, have a right to know? Can and should insurance companies have access to genetic information? What is the right to privacy for research?

If you agree to testing are you obliged to pursue treatments? What is the "right" to hide a genetic condition within families (for example, couples, marriage contracts)? Would stringent divulgence regulations dissuade people from having a genetic test?

(2) Is genetic screening inherently discriminatory and therefore contradictory to the position that all human beings, including those with genetic disorders, are equally valued?

(3) How can the social conditions of informed choice be established around gene technology?

What is the role of counselling? Is "consultation" a better approach/term than "counselling". Is human sensitivity lacking in counselling? Do genetic counsellors not take account of a person's particular needs or prior knowledge or education? Do not people need to be empowered to take responsibility by being well informed, rather than being instructed what to do by experts? Why are there no references to support groups in a lot of cases when a genetic disorder is diagnosed?

\section{Theme 2: legislative concerns}

(4) Who will impose regulation/controls? Will regulations/controls be voluntary or compulsory?

What happens when there is diagnosis of late-onset conditions that don't develop? What are the effects of unnecessary stress from this "mis-diagnosis", where a probability of a disease occurring may be interpreted as a certainty? Is individual choice enough, given the entire social context choices related to gene technology?

(5) How can we have a legislative framework which can keep abreast of scientific developments and contemporary community values? Should not legislators stay abreast of gene technology developments as well as social perspectives on the technology?

\section{Theme 3: research priorities}

(6) Who will benefit from gene technology given financial limitations? What does it replace? Who decides if gene technology is of more social value than other approaches?

Is too much money/resources spent on gene technology and not enough on causes (for example, environmental, nutritional)? Is there enough research on genetic disorders arising recently without history of inheritance (for example, environment, nutritional factors, reduced sperm numbers etc...)?

(7) Is gene technology motivated by private ownership/profit rather than the betterment of humanity?

For what percentage of the population will gene technology have benefits and are those finances going to be diverted from some other part of the health budget? Is it a cure for present and future generations? Is there a requirement for three generational follow-up. Who, if anyone is going to provide this long term support?

(8) Who pays for it? Who selects? Who gets it?

Have financial aspects been sufficiently considered: costs/benefits, for example, smoking and health costs versus tobacco industry profits and taxes?

\section{Theme 4: wider considerations}

(9) What gene intervention is off limits? Who sets the end?

What are the limits of testing? Is the information balanced? What are the ethics of scientists involved in genetic research? What part does ethics play in their training? How are ethics committees appointed? Are science and technology running ahead of ethics?

(10) What individual values will be bought to bear in making gene-technology-related decisions and how can we ensure that these decisions will be made with compassionate and balanced motives?

(11) Is the rhetoric of individual choice sufficient to prevent the flourishing of a new eugenics programme?

(12) Given that gene therapy is already available and that germ line therapy is being done, why should we trust scientists to be responsible?

Is a Brave New World imminent? Is there a danger to human gene diversity? Are there unforeseen consequences of gene-technology modifications, as with the introduction of feral animals to the Australian ecology?

(13) How can we ensure the debate around gene technology is rational and not dominated by minority groups trying to impose their views on the wider community? 


\section{Workshop discussion}

The responses of the experts and discussions arising out of these questions are briefly summarised:

\section{Clinical considerations}

The initial set of questions led to a discussion of the principles and procedures of genetic counselling, particularly with respect to privacy issues. There were criticisms of a top-down approach to counselling, with the recommendation that it should be changed to reflect a more consultative approach. There was a degree of uncertainty amongst professional counsellors about the status of privacy with regard to gene technology. The current legal status of responsibilities of disclosure with regard to the insurance industry were clarified. The use of testing for the "elimination" of people was proposed as discriminatory; however, the legal issues about discrimination against living people and the moral issue about the status of the fetus were seen as different. It was also suggested that the practice of preimplantation diagnosis was required by the Hippocratic principle of "doing-less-harm" to which medical doctors are morally bound (ie transferring a defective embryo causes harm).

\section{Legislative concerns}

Who should, rather than who will regulate gene technology was raised as an issue. Regulations currently in place for gene therapy trials are already stringent. Another issue was: How could legislation keep abreast of research and community values? There is a widespread overestimation of the possibilities for, and positive impacts of, genetic screening, according to some members of the reference panel.

\section{Research priorities}

The conviction was expressed that environmental/ nutritional factors cause many of our contemporary genetic disorders. The issue of how the empowerment of community members - through provision of basic information about healthy living and self-diagnosis (such as SOMA produces) might undercut dependence upon, and thus the economic profitability of, pharmaceutical products, was raised. Biotechnology policy was seen as being "community driven"; one participant described her experience of the influence of doctors in shaping people's opinions. There was insufficient community discussion about what people wanted from gene technology, or, more generally, what the community priorities for health resources were.

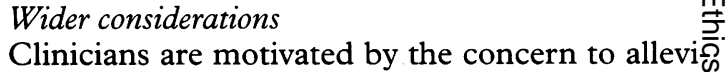
ate the suffering of patients (nothing would. necessarily be off limits if it contributed to this? aim). The claim was made that the power of gen technology pales into insignificance besides the power of nature; this argument has, of course? been central to many discourses on technologica\$ progress. It was suggested that gene technologts would just not be able to produce designer babies and the like, and thus community concerns of this kind were simply unfounded. Exaggerated claimsు are made about gene technology; it was empha sised how fora of this kind reveal that we - expert and lay people alike - are all ordinary peoplę struggling with difficult questions and contingent responsibilities. This question produced wide dis cussion about the need for legal and professionalo guidelines for making balanced decisions, bu none of the panellists took up the moderator's suggestion to discuss the personal aspect of devef oping a balanced stance. The final question fron the community participants about the undue influence of minority groups, produced discussione about the need for clear legal, regulatory frameworks.

\section{Conclusions}

In this brief report, two broad conclusions may be्षे drawn from the workshop.

The first concerns the nature and range of questions raised. The set of questions arose out of a comparatively extended process of reflection b groups of lay people and thus represent well considered concerns on the part of people with a active, continuing interest in the development of genetic medicine. An obvious characteristic of this set of questions is the emphasis on the broadero more contextual, social and ethical ramifications of the new genetics. Clearly, it is these kinds os questions which should be central to the continut ing public debate about the new genetics.

The second concerns the potential of this kind of workshop as a tool for broader public debate and public policy development. First, there is $\mathbb{R}$ positive benefit in identifying the range of interested publics concerned with an issue an proactively involving them in a process of polic discussion. This more targeted approach may b more useful than trying to educate or inform "the general public". The kind of groups involved if the workshop bring to the discussion valuable background knowledge and experience which helps to contextualise effectively the more techn? cal discussions of medical experts. Also they are potentially "vitally interested allies" for the sciene tific and medical profession in the creation 
better forms of communication with the networks of people involved in disability support groups, alternative health activities and religious communities. Second, there is the value of the kind of conversation which this particular process generates. In contrast to more conventional public inquiries in which a discussion paper establishes the terms and topics for discussion, this process gives an opportunity to interested publics to shape the discussion in their own terms. Third, this kind of workshop provides a space for discussion between the medical profession and patients' groups that is more public than the clinical context and thus allows the policy concerns of these groups to be heard.

It is recognised that by itself, this sort of workshop is likely to have little continuing impact. However, we believe that it does have the potential to be used as a more proactive tool in the attempt to establish more effective communication between the scientific community and the medical profession on the one hand and a wider set of interested publics on the other. It could also be used in a process of policy formulation, for example, in the review of the Western Australian Reproductive Technology Act, which has been taking place over the past year or so.

In our view, the capacity of lay people with significant interests in gene technology issues to engage in community consultations is a particularly valuable resource for continuing policy development. We believe that the use of such processes to facilitate lay deliberation should be more actively developed for the purposes of both communicating new developments in genetics and involving lay publics in policy development.

\section{Acknowledgements}

The support for this Public Perceptions of Biotechnology project, by the Australian Research Council's large grants programme, 1994-6, and Murdoch University's Special Research Grants Scheme in 1997, is gratefully acknowledged. David Schibeci provided technical assistance to the project.

Renato Schibeci, * PhD, is Senior lecturer in Science Education, Murdoch University, Murdoch, Western Australian. Ian Barns, PhD, is Lecturer in Science and Technology Policy, Murdoch University. Robyn Shaw, BAppSc (Environmental Health), is a Research Assistant, Murdoch University. Aidan Davison, BSc(Hons), PGDip(STP), is a Research Assistant, Murdoch University. * Author for correspondence

\section{References}

1 Joss S, Durant J, eds Public participation in science: the role of consensus conferences in Europe. London: Science Museum, 1995.

2 Hamstra A. The role of the public in instruments of constructive technology assessment. See reference 1: 53-66.

3 Gamson W. Talking politics. Cambridge: Cambridge University Press, 1992.

4 Durant J, Hansen A, Bauer M. Public understanding of the new genetics. In: Marteau T, Richards $\mathrm{M}$, eds. The troubled helix: social and psychological implications of the new human genetics. Cambridge: Cambridge University Press, 1996: 235 - 48. 